\title{
ÍNDICE DE DESENVOLVIMENTO REGIONAL SUSTENTÁVEL APLICADO AOS MUNICÍPIOS DA REGIÃO METROPOLITANA DO CARIRI
}

\author{
SUSTAINABLE REGIONAL DEVELOPMENT INDEX APPLIED TO \\ MUNICIPALITIES OF THE CARIRI METROPOLITAN REGION
}

\author{
Mirelle Tainá Vieira Lima ${ }^{1}$ \\ Maria Inácio da Silva ${ }^{2}$ \\ Carlos Wagner Oliveira ${ }^{3}$ \\ Paulo Renato Alves Firmino ${ }^{4}$ \\ Joceam dos Santos Souza ${ }^{5}$
}

\begin{abstract}
Resumo
Índices ou indicadores de sustentabilidade são meios úteis para mensurar e avaliar o desenvolvimento de territórios e organizações. O presente trabalho buscou comparar o nível de desenvolvimento sustentável alcançado entre os nove municípios da Região Metropolitana do Cariri (RMC), analisando indicadores ambientais, econômicos e sociais. Os dados atualizados foram selecionados com base no documento IDS BRASIL (2014) do Instituto Brasileiro de Geografia e Estatística (IBGE), e coletados por meio das plataformas IBGE cidades, anuário do IPECE e Atlas Brasil. Os dados foram normalizados, facilitando a comparação de desempenho nas diversas dimensões da sustentabilidade. Depois de transformados em índices, os valores foram categorizados entre: crítico, estado de alerta, aceitável ou ideal. O conjunto de informações básicas que envolve renda e trabalho, educação, saúde, segurança, infraestrutura, acesso a políticas públicas de distribuição de renda, drenagem, saneamento, urbanização, vegetação, rendimentos, entre outros, e seus respectivos desempenhos, foi compilado e agregado por meio de uma média obtida a partir dos resultados individuais em cada município de estudo. Os municípios mais desenvolvidos da região são Juazeiro do Norte, Crato e Barbalha, nessa mesma ordem. Santana do Cariri é o município que necessita de maior atenção quanto ao seu desenvolvimento.
\end{abstract}

Palavras-chave: Dimensões da sustentabilidade. Cidades. Nível de desenvolvimento.

\footnotetext{
${ }^{1}$ Mestre em Desenvolvimento Regional Sustentável pela Universidade Federal do Cariri, Juazeiro do Norte - CE, Brasil. Email: mirellet.vieira@gmail.com

${ }^{2}$ Mestre em Desenvolvimento Regional Sustentável pela Universidade Federal do Cariri, Juazeiro do Norte - CE, Brasil. Email: nacymarim@gmail.com

${ }^{3}$ Doutor em Biosystems Engineering, University of Tennessee System. Professor da Universidade Federal do Cariri, Crato CE, Brasil. E-mail: carlos.oliveira@ufca.edu.br

${ }^{4}$ Doutor em Engenharia de Produção (UFPE). Professor da Universidade Federal do Cariri, Juazeiro do Norte - CE, Brasil. E-mail:praf62@gmail.com

${ }^{5}$ Acadêmico do Curso de Arquitetura e Urbanismo da Universidade Tiradentes (UNIT) - Campus Maceió - AL, Brasil. Email: joceamss@gmail.com
} 


\begin{abstract}
Sustainability indices or indicators have been useful for measuring and evaluating the development of territories and organizations. The present paper aimed to compare the level of sustainable development achieved among the nine cities of the Metropolitan Region of Cariri, Ceará (RMC), via environmental, economic, and social indicators. The updated data were selected based on the IDS BRASIL (2014) of the Brazilian Institute of Geography and Statistics (IBGE), and acquired through IBGE platforms like IPECE yearbook and Atlas Brazil. The data were normalized, facilitating the comparison of performance in the various dimensions of sustainability. After being transformed into indices, the values were classified into: critical, alert, acceptable or ideal. The set of basic information that involves income and labor, education, health, safety, infrastructure, access to public policies of income distribution, drainage, sanitation, urbanization, vegetation, yields, among others, and their respective performances, were then compiled and averaged per city. The most developed cities of the region are Juazeiro do Norte, Crato and Barbalha, in this order. Santana do Cariri is the city that needs more attention regarding its development.
\end{abstract}

Keywords: Sustainability dimensions. Cities. Development level.

\title{
Introdução
}

Há algumas décadas, o conceito de desenvolvimento não instigava reflexões que fossem além da compreensão de crescimento econômico. Com o passar dos anos, no entanto, a intensificação e a velocidade da globalização, junto às preocupações sobre os impactos causados por esse crescimento, dentre outros fatores, contribuíram para a expansão desse ponto de vista. Não se pode mais pensar o desenvolvimento de forma tão unilateral, visto que não há mais sentido pensá-lo longe das dimensões ambientais, sociais, culturais, institucionais e demais aspectos que abraçam a pluralidade das atuais sociedades humanas. Sachs, em 2009, reforça de forma concisa o desenvolvimento sustentável, como aquele que atende as necessidades presentes, sem comprometer as necessidades das gerações futuras.

De acordo com Feil \& Schreiber (2017), os termos sustentabilidade e desenvolvimento sustentável, apesar de serem usados de forma sinônima, têm conceitos diferentes. Para eles, o termo sustentabilidade tem origem e foco no viés ambiental, que decorre das preocupações ambientais acerca da deterioração da ecologia global em prol do desenvolvimento econômico, tendo relação com a solução da escassez de recursos naturais vinculados a questões energéticas e a recursos naturais, enquanto o desenvolvimento sustentável objetiva o crescimento econômico sem agredir o meio ambiente, propondo mudanças em longo prazo que vão além da perspectiva ambiental, mas que também envolvem o comportamento da humanidade, por meio de estratégias, de processos e de práticas.

No presente trabalho, serão apresentadas diversas maneiras de se mensurar o desenvolvimento sustentável por meio de índices e indicadores, mesmo sabendo que, pelo atual estado da arte, a sustentabilidade é imensurável. Carvalho \& Barcellos (2009) explicam em duas vertentes o porquê de a sustentabilidade ser imensurável. Primeiramente, afirmam que não há uma definição universal para sustentabilidade que possa ser aceita em todas as situações, não generalizada e precisa. Ou seja, não há um consenso acerca do conceito desse termo, considerando que ele se encontra em constante construção e mudança.

Nesse contexto, de acordo com Carvalho \& Barcellos (2009), a partir dos anos 80, os indicadores ambientais começaram a ser desenvolvidos em vários países europeus; no Canadá e na Nova Zelândia, que se consolidou no acordo gerado entre 179 países durante a Agenda 21, quando se afirmou a necessidade de se desenvolverem indicadores de desenvolvimento sustentável (IDS) por parte dos países signatários. No ano 2000, 147 chefes de estado e de governo de 189 países, incluindo o Brasil, reuniram-se na Cúpula do Milênio da ONU, em Nova York, comprometendo-se com os Objetivos de Desenvolvimento do Milênio (OMS) até 2015, por meio de ações específicas de combate à fome e à pobreza, de promoção de políticas de saúde, de saneamento, de educação, de habitação, de igualdade de gênero, de meio ambiente, entre outros. A fim de dar continuidade ao tratado após 
2015, os Objetivos de Desenvolvimento Sustentável (ODS) foram lançados no documento final da Conferência Rio+20 (2012), intitulado "O futuro que queremos", em que foram abertos grupos de trabalho intergovernamentais designados para a elaboração dos ODS (CARVALHO \& BARCELOS, 2015).

Para Abramovay (2010), os indicadores de desenvolvimento sustentável constituem uma ferramenta de grande potencial como via para a governança, em que a sistematização de indicadores de sustentabilidade implica a construção de um modelo capaz de refletir a cadeia causal das ações antrópicas (CARVALHO \& BARCELLOS, 2009).

Quanto ao conceito atribuído aos indicadores, pode se tratar de uma medida quantitativa ou qualitativa que carrega um valor intrínseco capaz de medir ou expressar informações sobre algum aspecto da realidade ou conceito. De acordo com o IBGE (2014), os indicadores de desenvolvimento sustentável são estatísticas, que podem ser valores absolutos, razões ou outros índices, utilizadas na mensuração do nível de sustentabilidade social, ambiental, econômica e institucional de uma sociedade ou território, em que buscam representar um elemento do mundo real através de um valor.

Conforme Silva et al. (2009), embora seja dificultoso eleger e reunir os principais fatores que influenciam no desenvolvimento, eles estão presentes em inquietações expressas relacionadas ao estilo de vida atual e futuro, à qualidade de vida, à prosperidade econômica e, de forma generalizada, ao futuro do planeta terra. Índices ou indicadores de sustentabilidade são meios úteis e de grande importância para descrever a sustentabilidade de sistemas, entretanto, faz-se necessário considerar seu real significado e alcance (SICHE et al., 2007).

Com base no exposto, o presente estudo pretende comparar, em uma escala local, o nível de desenvolvimento sustentável alcançado entre os nove municípios da Região Metropolitana do Cariri (RMC), analisando indicadores ambientais, econômicos e sociais. Mais especificamente, indicadores de órgãos governamentais, submetidos ao método de construção de índice desenvolvido pelo Instituto Interamericano de Cooperação para a Agricultura (IICA).

O presente trabalho foi subdividido em quatro seções que abordam, nesta mesma sequência: introdução; revisão bibliográfica, que abrange os temas desenvolvimento sustentável e índice de sustentabilidade; procedimentos metodológicos; resultados e discussões e conclusões.

\section{Conceitos fundamentais}

\section{Desenvolvimento sustentável}

O conceito de desenvolvimento sustentável se dá em meio a debates construídos historicamente. Para Veiga (2015), definir Desenvolvimento Sustentável é compreender o desenvolvimento em um contexto histórico, político e de questões socioeconômicas, desde a proteção dos direitos humanos, o acesso à educação e a condição participativa construída pela democracia. Já a problematização acerca da sustentabilidade incide no cenário de incertezas frente à humanidade e à biosfera, o uso dos recursos naturais e a demasiada escassez para sustentar as formas de produção e consumo, sendo reconhecida a necessidade de buscar estratégias de sustentabilidade econômica, social e ambiental.

Desse modo, faz-se necessário integrar dimensões da sustentabilidade no processo de construção do conhecimento. Por vezes, a sustentabilidade se refere aos recursos naturais; por outras, aos derivados desses recursos. Alguns autores se referem aos níveis de produção, ou ainda dos níveis de consumo. Outro ponto diz respeito à noção de temporalidade subjacente ao conceito de desenvolvimento sustentável, considerando um sistema de referências do presente, para projetar um novo modelo futuro, considerando o atual modelo de produção capitalista e suas profundas desigualdades sociais (MARCOMIN; SILVA, 2009).

Os estudos sobre sustentabilidade atualmente encontram-se pautados não somente no bemestar social e no crescimento econômico, mas também no respeito à natureza, na transversalidade da ciência, dos impactos tecnológicos e da ética na relação homem-ambiente. As transformações requerem utilização de diferentes recursos didáticos, e desse modo é possível incitar o olhar aos impactos da globalização e das evoluções tecnológicas para pensar estratégias sustentáveis em longo prazo (BURSZTYN, 2001).

Sachs (1993) desenvolveu seus estudos na perspectiva de sustentabilidade que abrange aspectos sobre ecodesenvolvimento, respeitando a importância dos recursos naturais e ambientais, no entanto passou a ampliar a visão de desenvolvimento para a perspectiva sustentável, compreendendo a integralidade das dimensóes social, econômica, ecológica, espacial e cultural. 
Desse modo, pensar desenvolvimento sustentável é então apontar para a universalização efetiva dos direitos humanos (SACHS, 2008).

As mudanças nos convocam. A passividade humana não sustenta os paradigmas socioeconômicos, nem tampouco sustentarão as demandas ambientais e humanas que emergem na contemporaneidade. Para Sachs (2008), faz-se necessário abordar os problemas sociais de maneira holística, não se detendo apenas ao manejo da gestão dos recursos naturais, mas também às possibilidades de transformações do padrão civilizatório contemporâneo.

Nesse sentido, compreender o desenvolvimento sustentável é ampliar o campo de alcance da interdisciplinaridade, refletir sobre a condição humana de pertencimento e potencial. Jara e Souto (2001) expressam a necessidade de submergir em dimensões intangíveis que apontam para além dos fatores explícitos, ressaltando aspectos implícitos e subjetivos do desenvolvimento sustentável, ressaltando a importância do capital social, cultural e humano no processo de desenvolvimento sustentável.

O desenvolvimento sustentável abrange uma série de especificidades sociais, ambientais, institucionais, culturais e econômicas e é intrínseca ao seu conceito a necessidade de mecanismos ou ferramentas que avaliem as condições de dada localidade sob o ponto de vista de suas vulnerabilidades e potencialidades sustentáveis.

Para autores como Sachs (2008), o desenvolvimento sustentável envolve dimensões tradicionais como a econômica, a social e a ambiental, as quais constituem áreas abrangentes da atividade social, e são componentes de uma trajetória de desenvolvimento relacionada à identificação de objetivos específicos na avaliação de desempenho para modificação de dada localidade. Considerando que o conjunto de variáveis apresenta diferentes unidades de medidas que impossibilita a agregação em suas respectivas dimensões e a análise adequada da sustentabilidade, é necessária a transformação dessas variáveis em índices para permitir a agregação nas respectivas dimensões.

\section{Índices de sustentabilidade}

Fortalecendo o conceito de Carvalho \& Barcellos (2009), os indicadores constituem um valor absoluto (quantidade real) ou relativo (porcentagem), bem como uma função de vários outros indicadores (indicador composto ou índice), que pode ser objetivo e quantitativo ou qualitativo e subjetivo, constituindo uma relação inversamente ou diretamente proporcional entre fatores ou a mensuração sobre a efetividade social de determinada ação.

A palavra "indicador" tem etimologia latina (indicare) e significa apontar. Em uma análise estatística, um indicador pode ser denominado de variável (VAN BELLEN, 2004). Uma das principais funções dos índices e indicadores é simplificar fenômenos e informações complexas por meio da quantificação, que facilita a análise, a comparação e uma melhor compreensão, tornando possível a tomada de decisões inteligentes.

O desenvolvimento sustentável envolve aspectos plurais com enfoques diferenciados, oriundos de diferentes dimensões, os quais se refletem nos sistemas de indicadores. A definição das dimensões e variáveis depende da realidade dos territórios analisados, que são delimitados de forma multidimensional a fim de perceber as diferenças e identidades próprias (MARTINS \& CÂNDIDO, 2011).

O índice utilizado no presente trabalho é uma ferramenta metodológica desenvolvida por Sepúlveda (2005) no Instituto Interamericano de Cooperação para a Agricultura (IICA), que permite a verificação de processo de desenvolvimento sustentável em alguns países da América Latina. Essa metodologia consiste na coleta e sistematização de indicadores representativos de um conjunto de dimensões do desenvolvimento sustentável, que permite a realização de avaliações rápidas, bem como análise comparativa dos níveis de desenvolvimento sustentável em diferentes territórios.

\section{Procedimentos metodológicos}

O universo da pesquisa compreende a região de estudo, composta pelos nove municípios da região metropolitana do Cariri cearense, sendo eles: Juazeiro do Norte, Crato, Barbalha, Caririaçu, Farias Brito, Missão Velha, Nova Olinda, Jardim e Santana do Cariri (Figura 1). 
Figura 1: Mapa de localização da região metropolitana do Cariri cearense

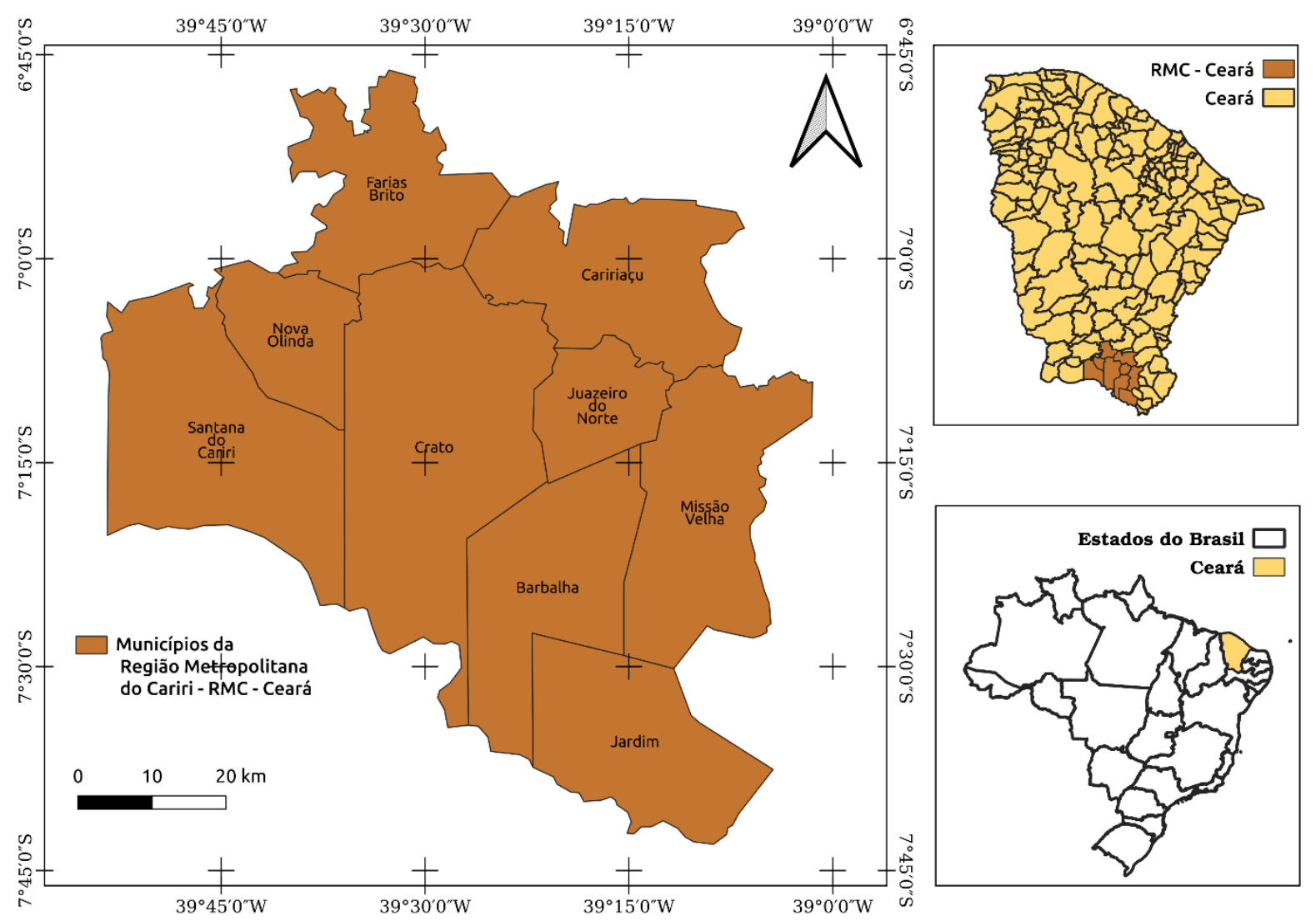

Fonte: Autores (2020).

A região do Cariri está inserida na região semiárida do nordeste brasileiro, porém tem peculiaridades na vegetação em relação às áreas de entorno, guardando resquícios de mata atlântica, presentes em abundância na Floresta Nacional do Araripe (FLONA) e umidade superior promovida pela "depressão do Cariri", principalmente nos municípios de Crato, Juazeiro do Norte e Barbalha (BRANDÃO, 2014). A Floresta Nacional do Araripe foi uma das primeiras áreas protegidas do Brasil e a primeira criada no Brasil, por meio do Decreto $\mathrm{N}^{\circ}$ 9.226, em 02 de maio de 1946. De acordo com o órgão responsável pela sua administração, o ICMBio, com sede no município de Crato/CE, ela foi criada para manter as fontes de água do semiárido e barrar o avanço da desertificação no Nordeste, e atualmente constitui uma unidade de conservação (UC). A FLONA/ARARIPE abriga uma grande diversidade de espécies, que mantem o equilíbrio hidrológico, climático, ecológico e edáfico do Complexo Sedimentar do Araripe e tem importância social e econômica, por suscitar a extração de produtos alimentícios.

Do ponto de vista do levantamento e da natureza dos dados, a pesquisa se caracteriza como documental e bibliográfica, visto que se baseou apenas na aquisição de dados secundários relevantes ao tema. Quanto às características do estudo, trata-se de uma pesquisa exploratória e descritiva, que busca compreender fenômenos a partir da avaliação de dados em um determinado período de tempo.

Os dados atualizados foram selecionados (Quadro 1) com base no documento IDS BRASIL (2014) do Instituto Brasileiro de Geografia e Estatística (IBGE) e coletados por meio da plataforma IBGE cidades, dos relatórios de perfil municipal disponibilizado pelo Instituto de Pesquisa e Estratégia Econômica do Ceará (IPECE) e do Atlas Brasil. O Atlas do Desenvolvimento Humano no Brasil é uma plataforma de consulta aos Índices de Desenvolvimento dos municípios, estados e regiões brasileiras, que engloba mais de 200 indicadores de demografia, educação, renda, trabalho, habitação e vulnerabilidade, com dados extraídos dos Censos Demográficos de 1991, 2000 e 2010. Ele foi utilizado como fonte de dados no presente estudo e constitui uma ferramenta simples, amigável e de fácil acesso, que facilita o manuseio de dados e estimula análises, oferecendo uma importante visão do panorama do desenvolvimento humano e da desigualdade interna em escala municipal (ATLAS, 2018). Os valores de domicílios beneficiados por coleta de lixo, abastecimento 
de água e volume de água tratada publicados pelo IGBE (2010) foram divididos pelo número de domicílios de cada município, a fim de refletir mais fielmente as condições disponibilizadas, de forma proporcional. Da plataforma DATUSUS foram retirados os dados referentes ao número de famílias beneficiadas pelo Bolsa Família e o número de famílias que estão fora da extrema pobreza graças ao auxílio do Bolsa família. Os dados de número de homicídios e Taxa de homicídio (Óbitos/100 mil hab.) foram retirados do Ministério de desenvolvimento Social (MDS). Cada indicador foi adquirido em função dos dados mais recentes disponibilizados pelos órgãos pesquisados.

Quadro 1: Dados selecionados para participar da amostra de variáveis analisadas em cada dimensão da sustentabilidade, presentes nos municípios

\begin{tabular}{|c|c|c|}
\hline \multicolumn{3}{|l|}{ Dimensão Social } \\
\hline Indicador & Unidade & Fonte (Ano) \\
\hline Analfabetismo & $\%$ & IBGE (2010) \\
\hline Esperança de vida & Anos & ATLAS (2010) \\
\hline Mortalidade infantil & $\%$ & IBGE (2014) \\
\hline Densidade demográfica & $\%$ & IBGE (2010) \\
\hline Razão de dependência & $\%$ & ATLAS (2010) \\
\hline Índice de desenvolvimento municipal & Coeficiente & IPECE(2016) \\
\hline Índice de desenvolvimento social & Coeficiente & IPECE (2015) \\
\hline Índice de desenvolvimento humano & Coeficiente & IBGE (2010) \\
\hline Total de estabelecimentos de saúde por mil habitantes & Unid./100 hab. & IBGE (2010) \\
\hline Taxa de escolarização ens. Infantil & $\%$ & IPECE (2015) \\
\hline Taxa de escolarização ens. Fundamental & $\%$ & IPECE (2015) \\
\hline Taxa de escolarização ens. Médio & $\%$ & IPECE (2015) \\
\hline População em domicílios com água encanada & $\%$ & ATLAS (2010) \\
\hline População com banheiro e água encanada & $\%$ & ATLAS (2010) \\
\hline População reside com $>2$ pessoas por dormitório & $\%$ & ATLAS (2010) \\
\hline População em domicílios com coleta de lixo & $\%$ & ATLAS (2010) \\
\hline População em domicílios com energia elétrica & $\%$ & ATLAS (2010) \\
\hline Pessoas em domicílios com paredes inadequadas & $\%$ & ATLAS (2010) \\
\hline População total em domicílios particulares permanentes & Habitantes & ATLAS (2010) \\
\hline Número de Famílias beneficiadas pelo Bolsa Família & Famílias & MDS (2018) \\
\hline Famílias fora da extrema pobreza devido Bolsa família & Famílias & MDS (2018) \\
\hline Número de homicídios & Óbitos & Datasus (2013) \\
\hline Taxa de homicídio & Óbitos/100 mil hab. & Datasus (2013) \\
\hline \multicolumn{3}{|l|}{ Dimensão Ambiental } \\
\hline Indicador & Unidade & Fonte (Ano) \\
\hline Frota veículos & Unidades & IBGE (2010) \\
\hline Arborização & $\%$ & IBGE (2010) \\
\hline Urbanização & $\%$ & IBGE (2010) \\
\hline Esgoto adequado & $\%$ & IBGE (2010) \\
\hline Esgoto inadequado & $\%$ & IBGE (2010) \\
\hline Esgoto semi-adequado & $\%$ & IBGE (2010) \\
\hline Coleta de Lixo & Domicílios & IBGE (2010) \\
\hline Abastecimento de água & Domicílios & IBGE (2010) \\
\hline Abastecimento de água em residências & Domicílios & IBGE (2010) \\
\hline Volume de água tratada & $\mathrm{m}^{3} / \mathrm{dia}$ & IBGE (2010) \\
\hline Área de lavoura permanente & Há & IBGE (2010) \\
\hline Área total destinada a APP & $\mathrm{Ha}$ & IBGE (2010) \\
\hline \multicolumn{3}{|l|}{ Dimensão Econômica } \\
\hline Indicador & Unidade & Fonte (Ano) \\
\hline Índice Gini da renda & Coeficiente & IBGE (2010) \\
\hline População ocupada & Habitantes & IBGE (2015) \\
\hline Taxa de pobreza & $\%$ & IBGE (2010) \\
\hline Salário médio mensal dos trabalhadores formais & Salários mínimos & IBGE (2015) \\
\hline PIB per capita & $\mathrm{R} \$$ & IBGE (2010) \\
\hline Finanças municipais & $\mathrm{R} \$$ & IPECE (2015) \\
\hline Consumo de energia elétrica & Mwh & IPECE (2015) \\
\hline PIB A PREÇOS CORRENTES & $(\mathrm{X} 1000) \mathrm{R} \$$ & IBGE (2015) \\
\hline
\end{tabular}


O método utilizado para transformar os valores brutos, com unidades de medida diferentes, em valores de índice corresponde de 0 a 1 , segue a metodologia utilizada por Waquil (2010) e foi operacionalizado a partir das seguintes equações de normalização:

Se a relação é positiva: $I=\frac{X-m}{M-m} \quad$ Se a relação é negativa: $I=\frac{M-x}{M-m}$

Em que,

I = índice calculado referente a cada variável, para cada município analisado;

$\mathrm{x}=$ valor observado específico para aquela variável e município;

$\mathrm{m}=$ valor mínimo observado;

$\mathrm{M}=$ valor máximo observado.

Depois de transformados em índices, comparando-se os resultados dos municípios entre si, os valores foram classificados de acordo com o seu desempenho, conforme a Tabela 1 a seguir:

Tabela 1: Classificação do índice de sustentabilidade

\begin{tabular}{lll}
\hline İndice (intervalo) & Desempenho & Cor \\
\hline 0,0000 e 0,2500 & Situação crítica & Vermelho \\
0,2501 e 0,5000 & Situação de alerta & Amarelo \\
0,5001 e 0,7500 & Situação aceitável & Verde claro \\
0,7501 e 1,0000 & Situação Ideal & Verde escuro \\
\hline
\end{tabular}

\section{Resultados e discussão}

O apurado de informações pertinentes ao desenvolvimento dos municípios, seja na esfera social, na econômica, ou na ambiental, apresenta-se a seguir.

\section{Dimensão Social}

O conjunto de informações básicas que envolvem renda e trabalho, educação, saúde, segurança, infraestrutura, acesso às políticas públicas de distribuição de renda e seus respectivos desempenhos, oriundo da média aritmética dos resultados individuais obtidos em cada município de estudo, seguem na tabela 2.

Tabela 2: Conjunto de Indicadores da Dimensão Social, considerando a média de cada uma das variáveis nos municípios da RMC, extraídos a partir de dados selecionados entre os anos 2010 e 2016

\begin{tabular}{lll}
\hline Indicador & Índice & Desempenho \\
\hline População total em domicílios particulares permanentes & 0,206 & Situação crítica \\
Número de famílias beneficiadas pelo Bolsa Família & 0,232 & Situação crítica \\
Total de estabelecimentos de saúde por mil habitantes & 0,323 & Situação de alerta \\
Índice de desenvolvimento municipal & 0,370 & Situação de alerta \\
População em domicílios com coleta de lixo (\%) & 0,378 & Situação de alerta \\
Taxa de escolarização ensino médio & 0,424 & Situação de alerta \\
Analfabetismo & 0,457 & Situação de alerta \\
Índice de desenvolvimento humano & 0,471 & Situação de alerta \\
Índice de desenvolvimento social & 0,478 & Situação de alerta \\
População em domicílios com água encanada (\%) & 0,506 & Situação aceitável \\
População com banheiro e água encanada (\%) & 0,513 & Situação aceitável \\
Pessoas em domicílios com paredes inadequadas & 0,525 & Situação aceitável \\
Taxa de homicídio & 0,526 & Situação aceitável \\
Famílias fora da extrema pobreza devido Bolsa família & 0,529 & Situação aceitável \\
Taxa de escolarização ens. infantil & 0,531 & Situação aceitável \\
Taxa de escolarização ens. fundamental & 0,532 & Situação aceitável \\
Razão de dependência & 0,537 & Situação aceitável \\
Mortalidade infantil & 0,559 & Situação aceitável \\
Esperança de vida & 0,571 & Situação aceitável \\
População reside com > 2 pessoas por dormitório (\%) & 0,615 & Situação aceitável \\
População em domicílios com energia elétrica (\%) & 0,734 & Situação aceitável \\
Número de homicídios & 0,800 & Situação ldeal \\
Densidade demográfica & 0,856 & Situação ldeal \\
\hline Média & $\mathbf{0 , 5 0 7}$ & Situação aceitável \\
\hline
\end{tabular}


Analisando os aspectos de educação, observamos que Crato, Juazeiro do Norte e Barbalha apresentam as menores taxas de analfabetismo, que corresponde, respectivamente, a 15; 16,2 e 18,7\%. Entretanto, municípios como Caririaçu e Santana do Cariri têm respectivos 31,7 e 29,9\%, que correspondem aproximadamente ao dobro do percentual. A taxa de escolarização nos ensinos infantil, fundamental e médio obtiveram um comportamento semelhante em todos os municípios. I infantil variou entre 47,61, em Caririaçu, 61,49, em Jardim. No ensino fundamental, em Barbalha, Jardim e Farias Brito, obteve-se 100\% de escolarização, e a menor taxa foi de $88,09 \%$, em Juazeiro do Norte. No ensino médio, variou de apenas $43,56 \%$, em Santana do Cariri, e $71,64 \%$, em Nova Olinda. Os dados de escolarização disponibilizados pelo IPECE (2016) são de fonte da SEDUC, que adotou a metodologia do INEP/MEC no cálculo deste indicador, para que possa ser compatível com outras unidades da federação.

Para Braga \& Mazzeo (2017), o Brasil possui um elevado número de pessoas com idade acima de 15 anos que não sabem ler e escrever. Baseado nos dados do Instituto Brasileiro de Geografia e Estatística - IBGE - (2015), por meio da Pesquisa Nacional por Amostra de Domicílios (Pnad), estimou-se que, em 2015, cerca de $8 \%$ da população era analfabeta (12,9 milhões de pessoas). Esse índice é exímio em revelar os contrastes presentes na sociedade brasileira, no que diz respeito às diferenças entre a regiões geográficas, gerações e raças. Observa-se que, dentre a população analfabeta, $16,2 \%$ se concentra no Nordeste, e cerca de $4 \%$, no Sudeste e no Sul; apenas 0,8\% são jovens de 15 a 19 anos, e de 22,3\%, entre pessoas com 60 anos ou mais; além de compor apenas $5 \%$ de analfabetos brancos e $11,2 \%$ pretos. Os dados indicam uma evidente correlação entre as taxas de analfabetismo e a pobreza, exclusão e baixo desenvolvimento econômico (BRAGA; MAZZEO, 2017).

A taxa de escolarização no ensino médio, bem como de analfabetismo são consideradas em situação de alerta nos municípios estudados e podem ser decorrentes da carência de oferta de vagas na rede pública de ensino ou das condições sociais de cada indivíduo, por muitas vezes ter de abandonar os estudos em detrimento do trabalho. Nesse caso, o estado seria capaz de mudar o "olhar" para esses jovens e trabalhar para garantir mais condições de estes terminarem o ensino médio. É fundamental, ainda, que esta escolarização respeite as características do educando: sua idade, condição econômica, gênero, raça, etnia e se vive em zona rural ou urbana.

Neste trabalho, a alta densidade demográfica foi considerada no cálculo como um fator negativo, inferindo uma relação negativa ao índice, visto que a alta concentração de pessoas em uma determinada área pode acarretar diversos problemas sociais, dados, muitas vezes, em função da insuficiência do estado em gerir recursos e suprir as necessidades daquela população. Alguns problemas inerentes a locais muito populosos e que podem ser facilmente observados, são: o acúmulo de lixo, a fácil disseminação de doenças, as deficiências na mobilidade urbana, a baixa infraestrutura, a baixa capacidade dos setores públicos em atender as demandas de saúde, educação, segurança, dentre outros fatores.

Entretanto, cabe à presente pesquisa identificar e ponderar os motivos pelos quais essas aglomerações se formam, pois, muitas vezes, as populações migram para os grandes centros urbanos em busca de uma melhor qualidade de vida e maior oferta de emprego. Portanto, outros fatores serão levados em consideração. Para ser sustentável, o município deve oferecer condições proporcionais ao tamanho da população. Como exemplo, podemos citar o município de Juazeiro do Norte, o qual possui a maior densidade demográfica da região. Enquanto Nova Olinda possui 20,7 pessoas por km², Juazeiro do Norte possui 1.004,45 pessoas por $\mathrm{km}^{2}$, seguido no ranque por Crato e Barbalha, mesmo estes tendo aproximadamente dez vezes menos densidade demográfica. No entanto, Juazeiro do Norte oferece $56,78 \%$ de todas as vagas de trabalho disponíveis para a região.

Quanto ao percentual da população que vive em domicílios com água encanada, há um contraste entre Juazeiro do Norte e Jardim, que têm um percentual de, respectivamente, 95,04 e $48,75 \%$ da população. Já quanto ao percentual da população que vive em domicílios com banheiro e água encanada, Santana do Cariri tem o menor índice, 44,32\%, e o maior, em Juazeiro do Norte, de 90,63\%. Em todos os municípios, o percentual da população que vive em domicílios com energia elétrica sempre ultrapassa os $92 \%$.

Diante do exposto, as autoridades responsáveis pelos municípios em questão, devem dedicar maior atenção a esses indicadores que são essenciais para o equilíbrio socioambiental. A ausência de saneamento básico e o acúmulo de resíduos sólidos de áreas urbanas e rurais apresentam riscos à saúde da população. Além disso, os riscos ambientais para a saúde incluem a falta de acesso à água potável, e pode ocasionar contaminação de alimentos com organismos patogênicos e proliferação de vetores de doenças (EZAKI, 2011). 
Nesse sentido, a expectativa de vida reflete se fatores inerentes à sociedade que garantem melhores condições de vida à população estão sendo proporcionados. Dentre os municípios estudados, Caririaçu tem a menor média, 68,81 anos, e Crato tem a melhor média, correspondente a 74,3 anos, de acordo com os dados do IBGE cidades (2010). Tomando como base o Japão, que constitui o país com maior expectativa de vida do mundo, 84 anos (APEX-BRASIL, 2015), o Cariri tem uma média distante, porém mais próxima da expectativa média dos brasileiros em 2010, que era de 73,5 anos de vida e que passou a ser 75,8 em 2018, conforme o IBGE.

Nova Olinda e Santana do Cariri têm o menor total de estabelecimentos de saúde por mil habitantes, apenas sete. Enquanto isso, Juazeiro do Norte possui uma razão de noventa e cinco unidades de saúde por habitantes. Construído em Juazeiro do Norte no ano de 2010, o Hospital Regional do Cariri foi o primeiro hospital público construído pelo governo estadual no interior do Ceará. Dispondo de $27.126,47 \mathrm{~m}^{2}$ e 294 leitos, assistindo a uma população de 1,5 milhão de habitantes, dos 44 municípios da macrorregião do Cariri (ISGH, 2017).

Frainer et al. (2017), aplicando metodologia semelhante no estado do Mato Grosso do Sul (MS), concluiu que o índice constitui um diagnóstico muito complexo para a análise da gestão pública. Sendo necessária, portanto, uma profunda interpretação das informações geradas, a fim de definir as melhores estratégias responsáveis por melhorar a qualificação de mão de obra, o investimento em ciência e tecnologia e o atendimento dos serviços públicos.

\section{Dimensão Ambiental}

Os dados elaborados a fim de analisar a dimensão ambiental, dentro do contexto de desenvolvimento regional sustentável, foram os mais elementares para se estimar e alcançar os objetivos da pesquisa, dada a complexidade do tema e as possibilidades que couberam ao presente estudo. Os dados selecionados estão dispostos da Tabela 3 a seguir.

Tabela 3: Conjunto de Indicadores da Dimensão Ambiental, considerando a média de cada uma das variáveis nos municípios da RMC, extraídos a partir de dados selecionados entre os anos 2010 e 2016

\begin{tabular}{lll}
\hline Indicador & Índice & Desempenho \\
\hline Área de lavoura permanente & 0,238 & Situação crítica \\
Área total destinada a APP & 0,356 & Situação de alerta \\
Volume de água tratada & 0,358 & Situação de alerta \\
Coleta de lixo & 0,422 & Situação de alerta \\
Urbanização & 0,456 & Situação de alerta \\
Esgoto adequado & 0,467 & Situação de alerta \\
Abastecimento de água & 0,488 & Situação de alerta \\
Esgoto inadequado & 0,547 & Situação aceitável \\
Arborização & 0,610 & Situação aceitável \\
Esgoto semi-adequado & 0,644 & Situação aceitável \\
Frota veículos & 0,809 & Situação ldeal \\
\hline Média & $\mathbf{0 , 4 2 4}$ & Situação de alerta \\
\hline
\end{tabular}

Na dimensão ambiental, a elevada frota de veículos foi calculada como um ponto negativo no momento de submissão ao índice, visto que está diretamente relacionada à emissão de $\mathrm{CO} 2$ e contribui com o efeito estufa. Enquanto, em 2010, Santana do Cariri tinha 3.250 unidades de veículos, Juazeiro já apresentava um total de 109.058 unidades. Ao mesmo tempo em que representa um fator negativo ao meio ambiente, pode indicar o nível de desenvolvimento econômico e social, associado ao nível de urbanização, ao crescimento das cidades e da renda da população. De maneira geral, a frota de veículos na RMC encontra-se numa faixa ideal, na perspectiva ambiental, de acordo com o índice utilizado.

O nível de urbanização dos municípios que compõem a RMC apresentou situação de alerta, com baixo índice de áreas de lavoura permanente. A taxa de arborização inclui o mínimo de $64.7 \%$, em Nova Olinda, e máxima de 97,4\%, em Barbalha e Crato.

A gestão dos recursos hídricos é um fator que merece atenção, classificado no presente estudo como em estado de alerta. Embora seja um elemento essencial, a água pode trazer riscos à saúde se for de baixa qualidade e utilizada sem o tratamento adequado. Para a Organização Mundial da Saúde (OMS) e seus países membros, todas as pessoas, em quaisquer estágios de desenvolvimento 
e condições socioeconômicas têm o direito de ter acesso a um suprimento adequado de água potável e seguro. Seguro, nesse contexto, refere-se a uma oferta de água que não represente um risco significativo à saúde, que tenha quantidade suficiente para atender a todas as necessidades domésticas, que seja disponível continuamente e que tenha um custo acessível.

A região possui baixo percentual tanto de esgoto inadequado, como de esgoto adequado, a maioria dos esgotos encontram-se em situação semi-adequada. Apresenta média de $23,2 \%$ de esgoto inadequado, com mínima de 2,5\%, em Juazeiro, e máxima de 48,3\%, em Jardim; média de 24\% de esgoto adequado, com mínima de 5,2\%, em Caririaçu, e máxima de 45,6\%, em Juazeiro do Norte, e média de 52,7\% de esgoto semi-adequado, com mínima de 20,2\%, em Caririaçu, e máxima de 70,7\%, em Juazeiro do Norte. A coleta de lixo, abastecimento de água e volume de água tratada, em média, está em estado de alerta, dada a grande discrepância entre os municípios. Enquanto Juazeiro do Norte trata $93,58 \mathrm{~m}^{3} /$ dia, Farias Brito trata apenas $11,14 \mathrm{~m}^{3} /$ dia; enquanto Juazeiro do Norte abastece 90,38\% da população, Santana do Cariri abastece apenas 38,08\% e enquanto Juazeiro do Norte coleta o lixo de $92,67 \%$ dos domicílios, Jardim coleta de apenas 33,19\%.

Juazeiro do Norte constitui uma das cidades mais desenvolvidas e de maior taxa de crescimento do interior do estado do Ceará, entretanto, apesar de oferecer maiores oportunidades, concentra grandes problemas decorrentes do crescimento desordenado e do planejamento público ineficiente. $\mathrm{O}$ elevado índice de homicídios apresentado é preocupante, sendo necessária uma investigação detalhada dos fatores que interferiram e ocasionaram esses resultados, e que sejam desenvolvidas mais políticas públicas (eficientes e eficazes) e que sejam implantadas não somente nessas regiões estudadas, como também nas demais regiões do estado do Ceará e em outros estados brasileiros. Enquanto Jardim registrou 2 homicídios em 2013, Juazeiro do Norte registrou 140, com taxa de óbitos por 100 mil habitantes equivalente a 53,58\%. A segurança pública é um fator vital a ser observado pelos órgãos competentes.

No estudo realizado por Moura-Fé et al. (2019), intitulado "Região metropolitana do Cariri (RMC), Ceará: meio ambiente e sustentabilidade", afirma-se que, em que pese a importância socioeconômica da RMC no estado, um quadro complexo de problemáticas ambientais vem se estabelecendo, pari passu ao seu crescimento econômico e urbanístico, prejudicando a manutenção ambiental de diversos patrimônios naturais, bem como a sustentabilidade do modelo econômico estabelecido e em desenvolvimento.

\section{Dimensão Econômica}

Os dados que representam o setor econômico na região (Tabela 4) são resumidos, visto que, de certa forma, alguns aspectos já foram representados na dimensão social e compreendem basicamente o montante disponível para o município e para cada cidadão se a renda fosse dividida igualitariamente, bem como o consumo de energia elétrica, que pode indicar o nível de desenvolvimento das atividades econômicas presentes na indústria, no comércio, presença de equipamentos domésticos e afins.

Tabela 4: Conjunto de Indicadores da Dimensão Econômica considerando a média de cada uma das variáveis nos municípios da RMC, extraídos a partir de dados selecionados entre os anos 2010 e 2016

\begin{tabular}{lll}
\hline Indicador & Índice & Desempenho \\
\hline PIB a preços correntes & 0,183 & Situação crítica \\
Finanças municipais & 0,214 & Situação crítica \\
População ocupada & 0,363 & Situação de alerta \\
PIB per capita & 0,412 & Situação de alerta \\
Índice Gini da renda & 0,506 & Situação aceitável \\
Taxa de pobreza & 0,507 & Situação aceitável \\
Salário médio mensal dos trabalhadores formais & 0,644 & Situação aceitável \\
Consumo de energia elétrica & 0,813 & Situação Ideal \\
\hline Média & $\mathbf{0 , 4 0 5}$ & Situação de alerta \\
\hline
\end{tabular}

De acordo com Wolffenbüttel (2004), em texto vinculado à revista Desafios do Desenvolvimento (IPEA), o Índice de Gini é um instrumento utilizado para medir o grau de concentração de renda em um determinado grupo, marcando a diferença entre os rendimentos dos mais pobres e dos mais ricos, cujo resultado varia de zero a um. Nesse caso, se cada um dos 
indivíduos de toda a população concentrasse a mesma quantidade de renda, o valor do Índice de Gini seria 0 (zero), pois representa uma situação de igualdade, no oposto, o valor 1 (um) representaria uma situação extrema em que apenas uma pessoa detém toda a riqueza. O Índice de Gini entre os municípios de estudo se manteve entre 0,4 e 0,49, considerando que, de acordo com o IBGE, o Brasil obteve um Índice de Gini correspondente a 0,491, em 2015, os municípios estão de acordo com a média nacional.

Crato tem a menor taxa de pobreza, $44,3 \%$, contrastando com o município de Santana do Cariri, que tem $71,78 \%$. Esse percentual é calculado com base na população com renda familiar mensal per capita de até meio salário mínimo, em determinado espaço geográfico e de tempo. Apesar do programa Bolsa Família contribuir para que algumas famílias carentes possam sobreviver e estar fora da extrema pobreza, o índice do número de famílias beneficiadas é considerado crítico. Diante do exposto, é necessário que haja ampliação do programa para que mais famílias possam ser beneficiadas.

A Razão de Dependência compõe o número de pessoas dependentes no município ( 0 a 14 anos e maiores de 65 anos) sobre o total da população economicamente ativa (14 a 64 anos), multiplicado por 100. Na região, esse percentual se encontra entre 50,20\% (Crato) e 67,70\% (Santana do Cariri). Isso pode ser um indicador do nível de oportunidade de emprego entre jovens.

$\mathrm{Na}$ dimensão econômica, o consumo de energia é destaque, apresentando índice ideal. Entretanto, é necessário trabalhar cada vez mais na conservação, pois a economia de energia está associada não somente à redução de custos, mas também a fatores como a preservação de recursos naturais. Em relação ao meio ambiente, a economia de energia promove a preservação da água em muitas regiões do Brasil. A contenção no uso da energia elétrica pode ajudar no manejo do ciclo hidrológico brasileiro, considerando que quase toda a energia gerada no país é feita por hidrelétricas.

O produto interno bruto (PIB) per capita apresenta-se em situação de alerta, já o PIB a preços correntes, que representa o valor nominal bruto adquirido naquele ano, sem correção monetária pela inflação, arrecadado em todos os setores da sociedade, bem como as finanças municipais, que compreende o valor disponível pela prefeitura para a administração da cidade, ambas se encontram em situação crítica.

De acordo com o relatório da Cooperação e Desenvolvimento Econômico (OCDE, 2018), o Brasil precisa aumentar o investimento para poder crescer mais. $\mathrm{O}$ país ocupa uma das piores posições entre os países membros e parceiros do grupo. No ranking dos países da OCDE, o Brasil aparece na quarta pior posição de investimento em relação ao Produto Interno Bruto (PIB), considerados os valores de 1990 a 2016. Nesse período, o investimento do país não chegou a $20 \%$ do PIB - soma de todos os bens e serviços produzidos pelo país. $O$ nível do investimento tem declinado continuamente desde 2013 e está baixo na comparação internacional. O relatório ressalta que um maior nível de investimento elevaria o potencial de crescimento da economia e fortaleceria 0 crescimento da produtividade, possibilitando aumentos salariais sem colocar em risco a competitividade dos produtores domésticos.

Silva et al. (2018), aplicando a construção de um índice de desenvolvimento sustentável (IDS) e análise espacial das desigualdades nos municípios cearenses, identificou que a região do Cariri constitui um dos centros econômicos (urbanos e industriais) do Ceará, bem como um dos locais com maior nível de desenvolvimento sustentável no estado. No estudo supracitado, o município do Crato destaca-se no estado como um dos municípios com melhor desenvolvimento social.

\section{Visão geral municipal}

De acordo com a visão geral das dimensões por municípios, Crato, Juazeiro do Norte e Barbalha apresenta desempenho aceitável, cujo triângulo é formado pelas cidades consideradas melhor desenvolvidas da região. Os demais municípios: Missão Velha, Caririaçu, Jardim, Farias Brito e Nova Olinda apresentam-se em situação de alerta, seguido por Santana do Cariri, que apresenta situação crítica, quando comparada a outros municípios da região à qual pertence, uma vez que apresenta os menores índices nas três dimensões analisadas (Tabela 5). 
Tabela 5: Conjunto de Indicadores da Dimensão Social, Ambiental e Econômica nos municípios da Região Metropolitana do Cariri Cearense. Os melhores resultados por dimensão estão em negrito

\begin{tabular}{llllll}
\hline \multirow{2}{*}{ Município } & \multicolumn{2}{l}{ Dimensão } & \multirow{2}{*}{ Média } & \multirow{2}{*}{ Desempenho } \\
\cline { 2 - 4 } & Social & Ambiental & Econômica & & \\
\hline Santana do Cariri & 0,263 & 0,198 & 0,234 & 0,232 & Situação Crítica \\
Jardim & 0,428 & 0,257 & 0,345 & 0,343 & Situação de Alerta \\
Nova Olinda & 0,473 & 0,281 & 0,350 & 0,368 & Situação de Alerta \\
Farias Brito & 0,547 & 0,291 & 0,349 & 0,396 & Situação de Alerta \\
Caririaçu & 0,367 & 0,547 & 0,395 & 0,437 & Situação de Alerta \\
Missão Velha & 0,429 & 0,612 & 0,518 & 0,520 & Situação aceitável \\
Barbalha & 0,602 & 0,692 & 0,565 & 0,620 & Situação aceitável \\
Crato & 0,696 & 0,600 & 0,586 & 0,627 & Situação aceitável \\
Juazeiro do Norte & 0,641 & 0,546 & 0,756 & 0,647 & Situação aceitável \\
\hline
\end{tabular}

$\mathrm{Na}$ dimensão social, o Crato detém o maior índice comparado aos demais municípios. Na dimensão ambiental, o município de Barbalha se destaca com maior índice. A dimensão econômica é mais expressiva no município de Juazeiro do Norte. Isso pode estar diretamente relacionado com a religiosidade que impulsiona um fluxo constante de visitantes e romeiros e acaba ocasionando um crescimento econômico expressivo no município.

Resende et al. (2017), aplicando metodologia semelhante ao presente trabalho no município Barra do Garças (MT), identificou que o atual modelo de desenvolvimento econômico do município é insustentável, bem como o referido estudo pode fornecer informações à sociedade e ao poder público, capazes de nortear ações dentro do município.

Rodrigues e Rippel (2015), em seu ensaio "Desenvolvimento sustentável e técnicas de mensuração", apontam a falta de informação como um dos principais impedimentos à aplicação de índices de desenvolvimento municipal. Ressaltam que, em síntese, o desenvolvimento é econômico, social, ambiental e institucional. O próprio dinamismo desse conceito esclarece a importância de compreender o desenvolvimento por meio da construção de mecanismos de mensuração.

\section{Conclusões}

O desenvolvimento regional sustentável é um tema fundamental que deve ser discutido em todas as cidades, principalmente as de países subdesenvolvidos, que necessitam de estratégias para fomentar o seu desenvolvimento. Comparar os indicadores municipais, com os parâmetros alcançados pelo atual estado da arte, nos documentos formulados por estudiosos e organizações ao redor do mundo, são instrumentos poderosos para a transformação das sociedades e do meio ambiente e para o reavivar da esperança de garantir a sobrevivência e o bem-estar das futuras gerações.

Dentro dos parâmetros analisados, os municípios mais desenvolvidos da região, como de conhecimento geral, são Juazeiro do Norte, Crato e Barbalha e Missão Velha nesta mesma ordem. Santana do Cariri é o município que necessita de maior atenção do poder público, quanto à questão da sustentabilidade. No geral, as variáveis que apresentaram situação crítica foram: População total em domicílios particulares permanentes, Número de famílias beneficiadas pelo Bolsa Família, Área de lavoura permanente, Finanças municipais e PIB a preços correntes.

Os dados selecionados são suficientes para gerar um panorama mais generalizado da sustentabilidade e do desenvolvimento regional. Entretanto, devido à pluralidade da transitividade e da divergência de opiniões que envolvem o tema, esse diagnóstico, não necessariamente, determina um veredicto preciso da realidade, mas apenas de dentro das variáveis analisadas.

Como sugestão de estudos futuros, pode-se ampliar a discussão e aprofundar variáveis específicas, como a dispersão dos jovens quanto ao trabalho e ao estudo, frente às oportunidades que lhes são dadas; a erradicação de doenças ou a presença delas nos municípios; os cuidados com a preservação da fauna e da flora, preponderantemente na Chapada do Araripe, aproximando o estudo sobre o engajamento dos governos federal, estadual e municipal.

\section{Referências}


ABRAMOVAY, Ricardo. Desenvolvimento sustentável: qual a estratégia para o Brasil? Novos estudos - CEBRAP, n. 87, p. 97-113, 2010.

APEX-BRASIL - Agência Brasileira de Promoção de Exportações e Investimentos. Japão aspectos gerais, demografia e renda. 2015. Disponível em: <http://www.apexbrasil.com.br/Content/imagens/4896401b-f461-49b8-973e-823be68a72ae.pdf>

Acesso em: 30 nov. 2018.

BRANDÃO, R. L. Geodiversidade do estado do Ceará. Fortaleza: CPRM, 2014. 214 p.

BURSZTYN, M. (Org.). Ciência, ética e sustentabilidade: desafios ao novo século. São Paulo: Cortez; Brasília: UNESCO, 2001.

CARVAlHo, P. G. M. de.; BARCELlOS, F. C. Os Objetivos de Desenvolvimento do Milênio: uma avaliação crítica. Rio de Janeiro: IBGE, Diretoria de Pesquisas, 2015. 52 p.

CARVAlHO, P. G. M. de; BARCELlOS, F. C. Construindo indicadores de sustentabilidade. Indicadores Econômicos FEE, v. 37, n. 1, 2009.

EZAKI, S; HYPOLITO, R; PÉREZ-AGUILAR, A; MOSCHINI, F. A. Avaliação da qualidade das águas e sedimentos na microbacia hidrográfica do córrego do ajudante. Salto - São Paulo, UNESP, Geociências, v. 30, n. 3, 2011.

Frainer, D. M., SOUZA, C. C. D., REIS NETO, J. F., \& CASTELÃO, R. A. Uma aplicação do Índice de Desenvolvimento Sustentável aos municípios do estado de Mato Grosso do Sul. Interações (Campo Grande), v. 18, n. 2, p. 145-156, 2017.

IBGE. Vocabulário Básico de Recursos Naturais e Meio Ambiente. Rio de Janeiro: Instituto Brasileiro de Geografia e Estatística, 2 ed., 2004. 344p. ISBN: 8524037660

IBGE: Censo Demográfico e Pesquisa Nacional por Amostra de Domicílios (PNAD).

IPECE - Instituto de Pesquisa e Estratégia Econômica do Ceará. Anuário estatístico do Ceará 2017. Disponível em: < http://www2.ipece.ce.gov.br/publicacoes/anuario/anuario2017>. Acesso em: 30 nov. 2018.

JARA, C. J; SOUTO, M. V. M. As Dimensões Intangíveis do Desenvolvimento Sustentável. Brasília: IICA, 2001.

MARCOMIN, F. E; SILVA, A. D. V. Reflexões Acadêmicas: A sustentabilidade no ensino superior brasileiro: alguns elementos a partir da prática de educação ambiental na Universidade. Contrapontos - V. $9 \mathrm{n}^{0} 2$ - pp. 104 - 117 - Itajaí, mai/ago 2009.

MOURA-FÉ, M. M.; SILVA, M. J. A.; DIAS, V. P.; MONTEIRO, D. A.; SILVA, J. H.M.; RODRIGUES, R. M.. Região Metropolitana do Cariri (RMC), Ceará: meio ambiente e sustentabilidade. Revista da Casa da Geografia de Sobral (RCGS), v. 21, n. 2, p. 1198-1216, 2019.

OCDE- Relatório da Cooperação e Desenvolvimento Econômico. Publicado em 28/02/2018. Por ariana Tokarnia e Kelly Oliveira - Repórteres da Agência Brasil, Brasília. Disponível em: <http://agenciabrasil.ebc.com.br/economia/noticia/2018-02/ocde-recomenda-aumento-noinvestimento-para-o-brasil-poder-crescer >. Acesso em: 30 nov. 2018.

REZENDE, G. B.; CÂNDIDO, G. A.; REZENDE, H. L.; SILVA, f. P. Sustentabilidade de Barra do Garças sob a ótica do índice de desenvolvimento sustentável para municípios. Desenvolvimento em Questão, v. 15, n. 39, p. 203-235, 2017.

RODRIGUES, Katia Fabiane; RIPPEL, Ricardo. Desenvolvimento sustentável e técnicas de mensuração. Revista de Gestão Ambiental e Sustentabilidade, v. 4, n. 3, p. 73-88, 2015. 
SACHS, Ignacy. As cinco dimensões do ecodesenvolvimento. ESTRATÉGIAS de transição para o século XXI: desenvolvimento e meio ambiente. São Paulo: Studio Nobel, 1993.

SACHS, Ignacy. Caminhos para o Desenvolvimento Sustentável. $3^{\text {a }}$ edição. Rio de Janeiro: Garamond, 2008.

SEPÚLVEDA, S. Desenvolvimento microrregional sustentável: métodos para planejamento local. Brasília: IICA, 2005.

SICHE, Raúl et al. Índices versus indicadores: precisões conceituais na discussão da sustentabilidade de países. Ambiente \& sociedade, 2007.

SILVA, J. F. B. A., REBOUÇAS, S. M. D. P., ABREU, M. C. S. D., \& RIBEIRO, M. D. C. R. Construção de um índice de desenvolvimento sustentável e análise espacial das desigualdades nos municípios cearenses. Revista de Administração Pública, v. 52, n. 1, p. 149-168, 2018.

SIlvA, M. G.; CÂNDIDO, G. A.; MARTINS, M. F. Método de construção do índice de desenvolvimento local sustentável: uma proposta metodológica e aplicada. Revista Brasileira de Produtos Agroindustriais, Campina Grande, v. 11, n. 1, p. 55-72, 2009.

VEIGA, J. E da. Para entender o Desenvolvimento Sustentável. São Paulo: Ed.34, 2015.

WAQUIL, P. D. et al. Avaliação de desenvolvimento territorial em quatro territórios rurais no Brasil. Porto Alegre: UFRGS, 2006. Disponível em: <http://www8.ufrgs.br/ppge/pcientifica/2007_04.pdf>. Acesso em: 02 jul. 2020.

WOLFFENBÜTTEL, Andréa. O que é? Índice de Gini. Desafios do Desenvolvimento. Brasília: IPEA. 2004. Ano 1 . Edição 4. 1/11/2004. Disponível em: $<$ http://www.ipea.gov.br/desafios/index.php?option $=$ com_content\&id=2048: $\mathrm{catid}=28>$. Acesso em: 03 nov. 2018.

Ministério da Saúde. Indicadores e Dados Básicos - Brasil - 2012. Disponível em: <http://tabnet.datasus.gov.br/cgi/idb2012/matriz.htm >. Acesso em: 03 nov. 2018.

MDS, Ministério do Desenvolvimento Social. Bolsa Família e Cadastro Único no seu Município. Disponível em: <http://www.mds.gov.br/bolsafamilia >. Acesso em: 04 nov. 2018. MARTINS, M. F. \& CÂNDIDO, G. A. Índices de desenvolvimento sustentável para localidades: uma proposta metodológica de construção e análise. Revista de Gestão Social e Ambiental - RGSA, São Paulo, v. 5, n. 3, p. 03-19, set./dez. 2011.

VAN BELLEN, Hans Michael. Indicadores de sustentabilidade: um levantamento dos principais sistemas de avaliação. Cad. EBAPE. BR, Rio de Janeiro, v. 2, n. 1, p. 01-14, Mar. 2004. 